\title{
Identity of Naegleria strains isolated from organs of freshwater fishes
}

\author{
I. Dyková1, 2,* , I. Kyselová1,2, H. Pecková1, M. Oborník ${ }^{1,2}$, J. Lukeš¹,2 \\ ${ }^{1}$ Institute of Parasitology, Academy of Sciences of the Czech Republic, and ${ }^{2}$ Faculty of Biological Sciences, \\ University of South Bohemia, Branišovská 31, 37005 České Budějovice, Czech Republic
}

\begin{abstract}
Eighteen Naegleria strains were isolated from organs of freshwater fishes belonging to 5 species. Morphometric study allowed the separation of the Naegleria strains from the nonvahlkampfiid amoeboflagellates, but was inadequate for species determination. Six strains, representatives of groups that had a slightly different cyst size, were selected and corresponding derived clones were subjected to sequence analysis and riboprinting restriction fragment length polymorphism (RFLP)-PCR analysis of the small subunit (SSU) rRNA genes. One strain isolated from the brain of a fish with systemic infection was characterised by an intronless $2 \mathrm{~kb}$ long SSU rRNA gene and was identified as $N$. australiensis. Another 5 strains had a $1.3 \mathrm{~kb}$ long group I intron in their SSU rRNA gene and, based on the SSU rRNA sequences and riboprints, RFLP-PCR patterns appeared in phylogenetic trees to be closely related to Naegleria clarki.
\end{abstract}

KEY WORDS: Naegleria spp. · Fish strains $\cdot$ Molecular taxonomy $\cdot$ SSU rRNA

\section{INTRODUCTION}

The genus and species composition of amoebae that invade fish as well as their biology and host-parasite relations are of fundamental interest to fish pathologists because mortalities attributed to free-living amoebae have been reported in various species of cultured fishes. Unfortunately, even amoebae reported as the proven or the contributing factor of mortalities have not always been exactly determined, or adequately documented or stored for future identification. This also applies to species of the genus Naegleria Alexeieff, 1912, diagnosed in fish. Contrary to the considerable number of environmental Naegleria strains isolated since pioneering workers raised interest in the waterrelated human infections (primary amoebic meningoencephalitis), Naegleria strains isolated from organs of fish have only been recorded a few times. Taylor (1977), who screened organs of 23 species of freshwater fishes for the presence of small free-living amoebae, found amoebae of the genus Naegleria in 11 fish

*E-mail: iva@paru.cas.cz hosts. Naegleria gruberi was isolated along with other species of free-living amoebae from the intestinal contents of white suckers Catostomus commersoni and common shiners Notropis cornutus (Franke \& Mackiewicz 1982). Webb et al. (1998) tentatively identified a Naegleria sp. in fishes from the tidal James River, Virginia, USA. Naegleria fowleri, the causative agent of primary amoebic meningoencephalitis in humans, was described in 1970 (Carter 1970). Until that year any amoeba that had characteristics of the genus Naegleria was determined as N. gruberi Schardinger, 1899. As late as the 1980s any isolate that did not cause disease in mice was considered to be $N$. gruberi (De Jonckheere 1987). In the first taxonomic revision of freeliving amoebae, 5 species of the genus Naegleria were defined using morphology and isoenzyme analysis (De Jonckheere 1987). Since that time, molecular criteria, mainly partial small subunit (SSU) rRNA sequences, enabled the revision of species names and the establishment of new species of the genus Naegleria (De Jonckheere 1988, 1994a, 1998, Pernin \& De Jonckheere 1996, De Jonckheere \& Brown 1999). Recently the genus Naegleria was divided into 17 species (De Jonck- 
heere \& Brown 1999). Prior studies have not subjected Naegleria strains isolated from fish organs to molecular analyses. Several strains designated as isolated from tropical fish imports (De Jonckheere 1988) were actually isolated from aquarium water. One strain was isolated from the kidney of goldfish (see 'Discussion') but its molecular characteristic was not presented.

The intent of the present study was to determine selected Naegleria strains that were isolated from fish organs during our long-term study of free-living amoebae capable of colonising fish.

\section{MATERIALS AND METHODS}

Eighteen Naegleria strains isolated from organs of 18 freshwater fish belonging to 5 species and 1 hybrid were included in the study. Most of the fish (Blicca bjoerkna, Oncorhynchus mykiss, Perca fluviatilis, Salmo trutta and Salvelinus fontinalis) were collected in South Bohemia, Czech Republic, while the hybrid of Clarias macrocephalus $\times$ gariepinus was collected from a fish farm in Thailand. The agar-plate isolation, culturing, sub-culturing and cloning of amoebae were as described previously (De Jonckheere 1980, Dyková et al. 1997). All observations and measurements of living trophic amoebae were made in hanging drops. Cysts were observed and measured in wet mounts on an agar layer to fix them in a steady position, and in permanent mounts after impregnation using the method by Pussard \& Pons (1979). One clone was derived from each of the strains and used in further work. All clones were tested for production of temporary flagellated stages and subjected to morphological and morphometric analysis including observation in the transmission electron microscope. Six clones that had slight differences in cyst size were selected for molecular taxonomy. They are listed in Table 1 along with their origin and morphometric characteristics. Clones were grown in Bacto Casitone (BCS) medium that was changed daily (Červa 1969) enriched with ram serum and antibiotics (penicillin $100 \mathrm{U}$, streptomycin $100 \mu \mathrm{g}$ and neomycin $200 \mu \mathrm{g} \mathrm{ml}^{-1}$ ). In this medium the axenisation of clonal cultures was not achieved in fish clones (e.g., in clone CB2B/I not even after 53 passages). In Chang's serum casein glucose yeast extract medium, the growth of bacteria contaminating clonal cultures of naegleriae was even more massive. The Naegleria fowleri strain 0360 (obtained through the courtesy of Dr L. Červa) used as a control was maintained in axenic culture. Amoebae suspensions containing 1 to $3 \times 10^{8}$ cells ml $^{-1}$ were used for DNA extraction.

The method of DNA isolation followed basically the protocol by Maslov et al. (1996). Pelleted cells were suspended in NET $50(10 \mathrm{mM}$ Tris, $50 \mathrm{mM}$ EDTA, $100 \mathrm{mM} \mathrm{NaCl}, \mathrm{pH}$ 8.0) and lysed with Pronase E (Sigma, Aldrich, Prague) at the final concentration of $0.35 \mathrm{mg} \mathrm{ml}^{-1}$ and $3 \% \mathrm{~N}$-lauryl-sarcosyl (Sigma). The lysates were phenol/chloroform extracted and DNA was precipitated with ethanol, dissolved in distilled water and stored at $-20^{\circ} \mathrm{C}$. The SSU rRNA gene was amplified by PCR using the $5^{\prime}$ and $3^{\prime}$-end specific primers XY2 (TACCTGGTTGATCCTGCCAG) and Y25 (AAATGATCCCTACGCAGGTT) (Clark \& Cross 1988). PCR reactions were performed in a total volume of $25 \mu \mathrm{l}$ with $25 \mathrm{pmol}$ of each primer, reaction buffer, 10 nmol of deoxyribonucleoside-5' -triphosphates and $1 \mathrm{U}$ of Taq polymerase (TaKaRa, Prague) according to the manufacturer's instructions. The PCR conditions were as follows: DNA predenaturation at $95^{\circ} \mathrm{C}$ for 5 min was followed by 30 cycles of amplification that consisted of $94^{\circ} \mathrm{C}$ for $1 \mathrm{~min}, 50^{\circ} \mathrm{C}$ for $1 \mathrm{~min}$ and $72^{\circ} \mathrm{C}$ for $2 \mathrm{~min}$, and ended by an extension at $72^{\circ} \mathrm{C}$ for $8 \mathrm{~min}$. The PCR products were cloned into the $\mathrm{pCR}^{\circledR} 2.1$-TOPO cloning vector (Invitrogen, Groningen) and sequenced using the Big Dye kit (Perkin Elmer Applied BioSystems, Boston) on the ABI 377 automatic DNA sequencer. Parallel extraction, amplification and sequencing were performed on the Naegleria fowleri strain 0360. Sequences were assembled using the program SeqMan II (DNASTAR Inc., Madison, WI, USA) and aligned using the program CLUSTAL X (Thompson et al. 1997) with other available SSU rRNA sequences of amoebae of the genus Naegleria and family Vahlkampfiidae obtained from GenBank and analysed using the program PAUP (version 4.0b4, Sinauer Associates, Sunderland, MA, USA). The GenBank accession numbers for our sequences are as follows - clone Pd72Z/I: AF338417; 4177/I: AF338418; 4564/IV: AF 338419; 4709/I: AF338420; CB2B/I: AF338421;

Table 1. Origin of Naegleria clones subjected to molecular analyses

\begin{tabular}{|llllr|}
\hline Clone & Fish host & Organ & Locality & Cysts $(\mu \mathrm{m})$ \\
\hline 4709/I & Perca fluviatilis & Spleen & Černovický potok brook, Czech Rep. & $8.6(5.0-12.5)$ \\
4177/I & Blicca bjoerkna & Brain & Dvořiště pond, Czech Rep. & $9.1(7.0-12.5)$ \\
Pd56Z/I & Oncorhynchus mykiss & Gills & Černá brook, Czech Rep. & $9.8(8.0-12.5)$ \\
4564/IV & Perca fluviatilis & Kidney & Černovický potok brook, Czech Rep. & $10.6(8.0-13.0)$ \\
Pd72Z/I & Oncorhynchus mykiss & Gills & Černá farm, Czech Rep. & $10.7(8.7-14.5)$ \\
CB2B/I & Clarias (hybrid) & Brain & Fish farm, Thailand & $10.9(8.0-12.5)$ \\
\hline
\end{tabular}


Pd56Z/I: AF338422; and 0360: AF338423. For compared sequences, the accession numbers are N. lovaniensis U80062, N. minor X93224, N. jamiesoni U80061, N. andersoni U80057, N. gruberi M18732, N. italica U80060, N. australiensis U80058 and N. fowleri U80059.

The restriction fragment length polymorphism-PCR analysis of SSU rRNA genes (riboprints) was performed using the enzymes AluI and HinfI. The SSU riboprints recorded for Naegleria species by De Jonckheere (1994b) were used for comparison.

All strains and clones used in this study were cryopreserved and are stored in the culture collection of the Institute of Parasitology, Academy of Sciences of the Czech Republic, České Budějovice.

\section{RESULTS}

\section{Morphological analysis}

The strains belonging to the genus Naegleria were isolated from the gills of 11 specimens of Oncorhynchus mykiss, 1 specimen of Salvelinus fontinalis and various organs of the body cavity of 3 specimens of Perca fluviatilis and 1 specimen each of Blicca bjoerkna, Salmo trutta and Clarias hybrid. All strains were isolated from clinically healthy adult fishes. A systemic infection was diagnosed in the Clarias hybrid.

The shapes of moving and resting trophozoites of all Naegleria clones under study (Figs 1 to 7 ) were identical and corresponded to the taxonomic criteria set by Page (1967), who summarised several extensive descriptions of Naegleria spp. Amoebic trophozoites transformed into flagellated swimming stages within $30 \mathrm{~min}$ to $2 \mathrm{~h}$ after the agar plate cultures had been overlaid with water. In the majority of the flagellated forms 2 flagella were observed (Fig. 12). Examination of trophozoite ultrastructure revealed mitochondria with the discoid type of cristae (Figs 11 \& 14). This feature supported the generic diagnosis. All clones produced spherical cysts of identical type with a smooth, thick, refractile wall and a perinuclear layer of granules (Figs 8 \& 9). The wall consisted of a thick inner layer and a thin outer layer and contained pores with plugs (Figs 13 \& 15). Statistical analysis of cyst diameter revealed that only in cysts at least $6 \mathrm{~d}$ old did their diameter reach a constant value that could be used as a clonal characteristic. The comparison of cyst diameters provided the only criterion to sort our assemblage of morphologically similar Naegleria clones. The average diameters of cysts ranged from 8.6 to $14.2 \mu \mathrm{m}$ in individual clones. Six clones (Table 1), the average cyst diameters of which covered the range of our assemblage, were selected and determined as described below. Strains under study were isolated and cultured at $20^{\circ} \mathrm{C}$. With the exception of the clone $\mathrm{CB} 2 \mathrm{~B} / \mathrm{I}$ they did not tolerate $37^{\circ} \mathrm{C}$. The clone $\mathrm{CB} 2 \mathrm{~B} / \mathrm{I}$ was grown in 3 consecutive passages at $37^{\circ} \mathrm{C}$. It did not tolerate higher temperatures.

\section{Molecular analysis}

PCR amplification of the SSU rRNA genes divided the analysed assemblage of clones into 2 groups (Fig. 16). The first group, which consisted of 5 clones listed in Table 1 (4709/I, 4177/I, Pd56Z/I, 4564/IV and Pd72Z/I), was characterised by the SSU rRNA gene that was $3.3 \mathrm{~kb}$ long and contained an intron. Sequence analysis revealed that the introns are invariably $1305 \mathrm{bp}$ long and situated between nucloetide positions 630 and 631, and belong to the group I introns as described by Embley et al. (1992) and De Jonckheere (1993). The group I intron sequences in 5 clones were identical. They differed from group I intron in Naegleria clarki (EMBL No. X78281) in 3 bases out of $1305 \mathrm{nt}$. In all 5 clones the SSU rRNA gene is $1980 \mathrm{bp}$ long. The sequences differ from each other on the average in $4 \mathrm{bp}$, most of which were transitional. Except for clone $4177 / \mathrm{I}$, the riboprinting patterns obtained using the restriction enzymes AluI and HinfI (Fig. 17) were almost identical and were homologous to the riboprint of $N$. clarki (strain RU42) (De Jonckheere $1994 \mathrm{~b})$. In the $4177 / \mathrm{I}$ riboprint there was partial digestion with AluI (Fig. 17).

In the remaining clone CB2B/I as well as in Naegleria fowleri strain 0360, a $2 \mathrm{~kb}$ band was amplified with the SSU rRNA specific primers. The gene was 1980 and 1988 nt long in CB2B/I and 0360, respectively.

A search of GenBank identified Naegleria australiensis as the closest match to CB2B/I, and the strain 0360 was identical to $N$. fowleri. Phylogenetic analysis using maximum likelihood and maximum parsimony methods showed a similar result (Fig. 18). We confirmed a monophyly of the genus Naegleria within the family Vahlkampfiidae (data not shown). Within the genus Naegleria at least 3 monophyletic clades can be observed: $N$. fowleri and $N$. lovaniensis, $N$. andersoni and $N$. jamiesoni, and the biggest group involving $N$. clarki, N. gruberi, N. italica and N. australiensis. The 5 SSU rRNA intron-containing strains form a coherent group at the top of the third clade.

\section{DISCUSSION}

Discussing our results and those achieved by other authors, we can hardly avoid frequent use of 2 terms: strain and clone. The term 'strain' was used mostly in 


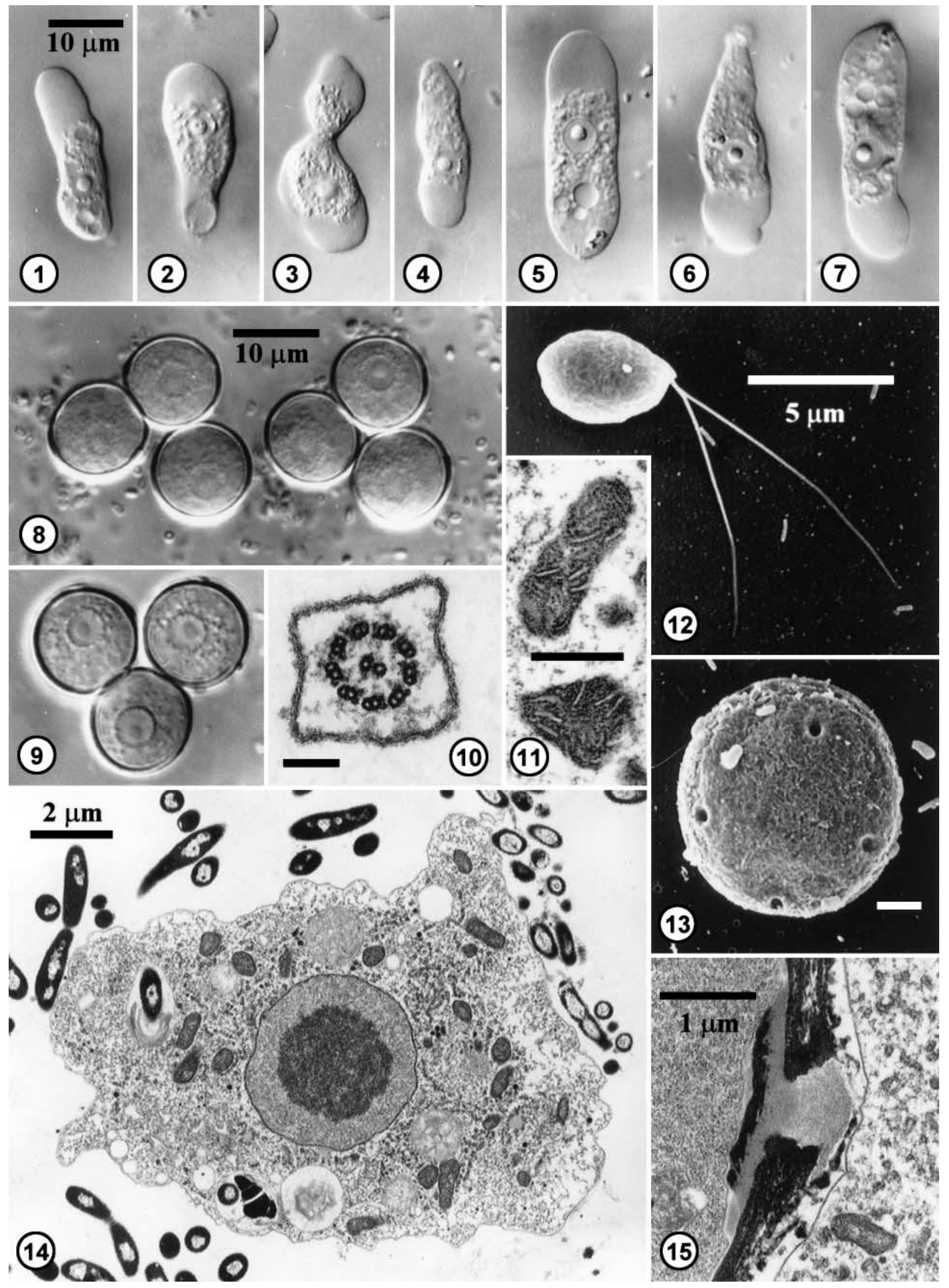


Figs 1 to 15. Morphology of Naegleria strains under study. Figs 1 to 7 . Representative trophozoites of 4 Naegleria strains isolated from organs of fishes as seen in hanging drops. Nomarski differential interference contrast. Scale bar in Fig. 1 applies to Figs 1 to 7. Figs 1 \& 2. Clone 4709/I. Fig. 3. Clone 4177/I. Fig. 4. Clone Pd56Z/I. Figs 5 to 7. Clone CB2B/I. Figs 8 \& 9. Cysts of Naegleria clones 4709/I and 4564/IV, respectively. Nomarski differential interference contrast. Scale bar applies to both figures. Fig. 10. Transverse section of the flagellum of the temporary flagellated stage (clone CB2B/I). Scale bar = 100 nm. Fig. 11. Mitochondria containing discoid cristae typical of the genus Naegleria. Scale bar $=500 \mathrm{~nm}$. Fig. 12. Scanning electron microscopy showing a trophozoite of the clone 4564/IV transformed into the flagellated form. Scale bar $=5 \mu \mathrm{m}$. Fig. 13. Scanning electron microscopy showing a cyst of the Naegleria strain $4709 /$ I with 4 pores. Scale bar $=2 \mu \mathrm{m}$. Fig. 14 . Transmission electron microscopy showing a trophozoite of the clone Pd72Z/I. Fig. 15. Transmission electron microscopy showing the cyst wall sectioned at the level of a plugged pore (clone Pd72Z/I)

previous papers, although actually clones derived from strains were used in those studies.

Trying to determine the isolated strains we faced the problem of species delineation in the genus Naegleria, which has a long history with many naegleriologists involved (De Jonckheere 1994a). Recently, using molecular techniques, the validity of 17 species was confirmed (De Jonckheere 1994a,b, De Jonckheere \& Brown 1999) including all upgraded subspecies. Among Naegleria strains studied and recorded in the literature thus far (De Jonckheere 1987, 1988, 1993, 1994a,b, De Jonckheere et al. 1984, Baverstock et al. 1989), our assemblage of strains isolated from fish organs is unique. Since amoebae isolated from gills of clinically healthy fish may be considered temporarily epizoic and strains derived from such isolates as belonging to the water environment, isolation of strains from liver, spleen, kidney and brain of fish shows the capability of Naegleria strains for an endozoic way of life in the heterotherm organisms. This stresses the necessity to clarify the pathogenic potential of Naegleria spp. for fish.

Sequence analysis of the SSU rRNA gene of 5 strains revealed a slight difference (4 bp) mostly considered as transitional. It is interesting to note that 5 strains isolated from different organs of different fish species collected in different localities showed the same restriction pattern and form a coherent group embracing

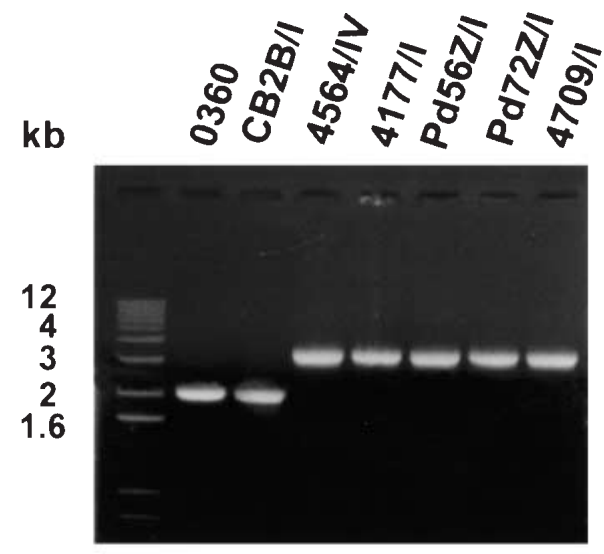

Fig. 16. PCR amplified small subunit rRNA gene of the Naegleria strains under study. Size marker on the left
Naegleria clarki. This species was established by De Jonckheere (1994a) for 2 strains (RU30 and RU42) as the only representatives of the species. Both strains were isolated from a hot spring in Rotorua, New Zealand, and tested as non-pathogenic for mice. Except for the type of culture medium we have no data on culturing conditions, including the temperature that was required by strains RU30 and RU42, to compare with the culture condition of the 5 clones that we assigned to the same species ( $N$. clarki). Therefore, we can only speculate that a Naegleria species might embrace strains that differ in their temperature tolerance. This assumption appears to be supported by data mentioned by De Jonckheere (1988) for N. australiensis, N. italica (formerly $N$. australiensis australiensis and $N$. australiensis italica, respectively) and $N$. gruberi. After his strains had been adapted to axenic culturing, they grew very well at temperatures that were lower than the highest temperature tolerated in monoxenic culture.

Since clone CB2B/I, which is the agent of systemic infection diagnosed in the Clarias hybrid, was identi-

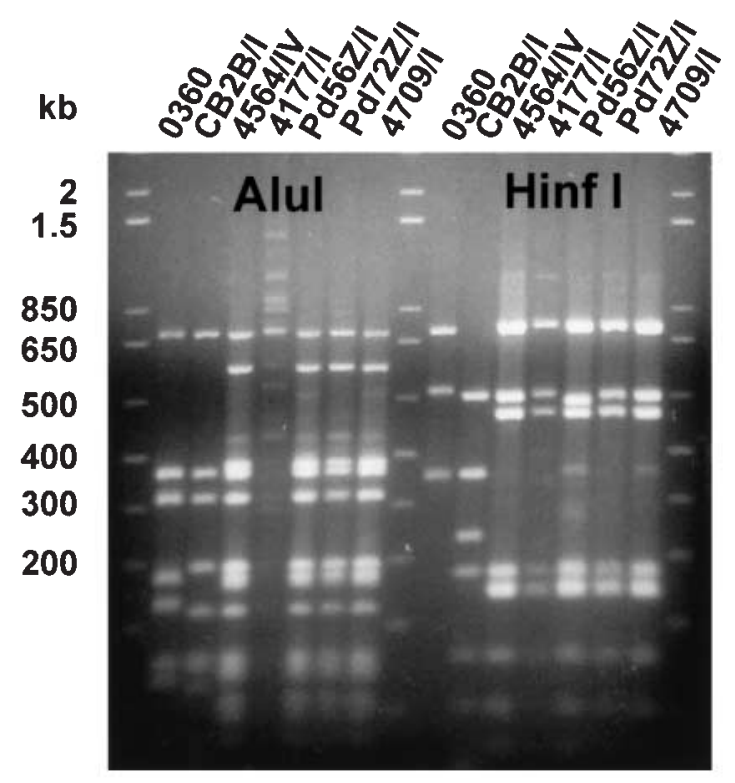

Fig. 17. AluI and HinfI riboprint patterns of Naegleria strains 


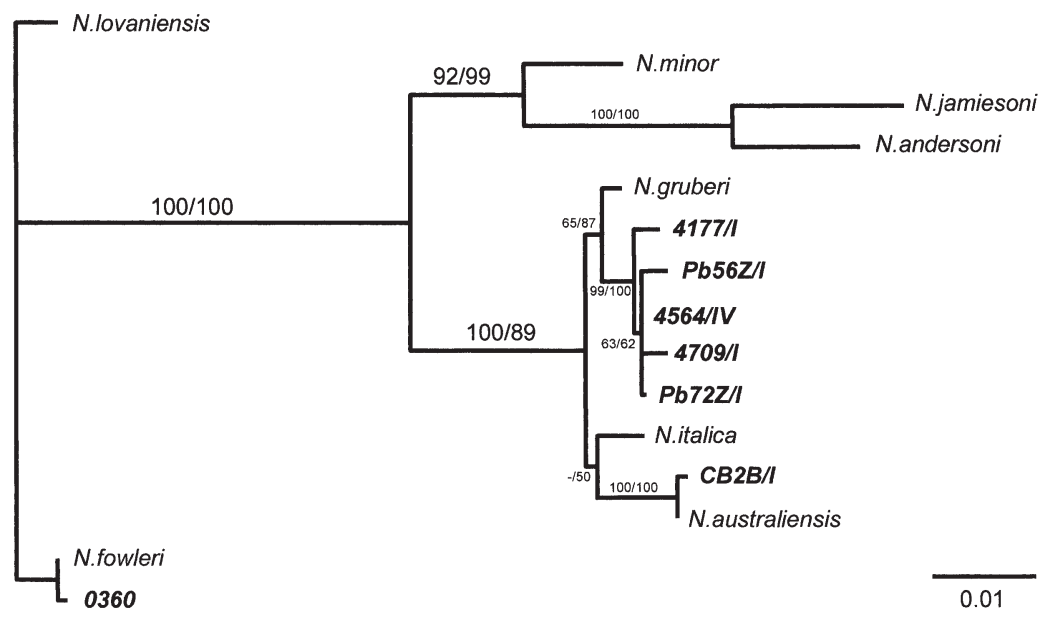

Fig. 18. Maximum likelihood phylogram $(-\mathrm{In}=4660.8)$ based on 1990 character long alignment (170 informative sites). The tree was rooted using Naegleria fowleri strain 0360 and $N$. lovaniensis as an outgroup. Newly obtained sequences are in bold. Maximum parsimony produced the 3 most parsimonious trees with a length of 315 steps and consistency index of 0.8 . The tree calculated by the distance method (general time reversal) had the best score of 0.152. Numbers on the branches indicate nodal support for 1000 replicates calculated by the maximum parsimony/distance method (general time reversal) different positions. In this study we used NEG-M N. gruberi. Five strains with intron branched in the same position as $N$. clarki and a sister group of $N$. gruberi, $N$. italica and $N$. australiensis, in line with the results of Pélandakis et al. (2000). There is no sequence of N. clarki in GenBank, but our riboprint results permitted us to compare the restriction pattern with that of N. clarki (RU-42), which helped us to identify our strains and to compare group I intron sequences.

The results obtained thus far suggest the need for further study of fish isolates and indicate that fish hosts may yield important material for research on Naegleria spp. and for studies on their distribution in the aquatic environment.

Acknowledgements. This research was funded by the Grant Agency of the Academy of Sciences of the Czech Republic (Project No. A6022802) and by the Ministry of Education (Project No. MSM123100003).

\section{LITERATURE CITED}

fied as Naegleria australiensis, the ability of the clone to colonise both hetero- and homoiotherm organisms along with its pathogenicity for mice have to be tested experimentally. The virulence and pathogenicity of the type strain of $N$. australiensis (PP 397) were tested repeatedly and the pathogenicity was proved after intracerebral inoculation of axenically grown amoebae (De Jonckheere 1981). There was also 1 strain isolated in 1989 from kidney of goldfish Carassius auratus deposited in ATCC (50387) and identified later as N. australiensis (De Jonckheere pers. comm.).

Surprisingly, none of our determined clones were grouped with Naegleria gruberi, considered for a long time to be widely distributed. Although the attempts at separating Naegleria species or morphotypes on the basis of cyst morphology (Page 1975, Pussard \& Pons 1979) have proved unreliable (De Jonckheere 1987, 1988, Pernin \& de Jonckheere 1996), the differences in average cyst diameter were used in our study as an arbitrary method for clone selection. However, our results confirmed that the morphometric characteristics of individual clones, which were extremely variable, could not be aligned with the results based on molecular criteria (see, for example, the difference in average cyst diameters in strains related to N. clarki; Table 1).

Phylogenetic analysis based on the SSU rRNA sequences showed results similar to those given by Pélandakis et al. (2000). It has been shown previously that the results of phylogenetic analysis depend on the Naegleria gruberi strains used. It is known that there are 4 clusters within the $N$. gruberi species that branch in
Baverstock PR, Illana S, Christy PE, Robinson BS, Johnson AM (1989) srRNA evolution and phylogenetic relationships of the genus Naegleria (Protista: Rhizopoda). Mol Biol Evol 6:243-257

Carter RF (1970) Description of a Naegleria sp. isolated from two cases of primary amoebic meningoencephalitis, and the experimental pathological changes induced by it. J Pathol 100:217-244

Červa L (1969) Axenic culture of Naegleria. Science 163:576

Clark CG, Cross GAM (1988) Small-subunit ribosomal RNA sequence from Naegleria gruberi supports the polyphyletic origin of amoebas. Mol Biol Evol 5:512-518

De Jonckheere JF (1980) Growth characteristics, cytopathic effect in cell culture, and virulence in mice of 36 type strains belonging to 19 different Acanthamoeba spp. Appl Environ Microbiol 39:681-685

De Jonckheere JF (1981) Naegleria australiensis sp. nov., another pathogenic Naegleria from water. Protistologica 17: $423-429$

De Jonckheere JF (1987) Taxonomy. In: Rondanelli EG (ed) Amphizoic amoebae. Human pathology. Piccin Nuova Libraria, Padova, p 25-48

De Jonckheere JF (1988) Naegleria andersoni n. sp., a cosmopolitan amoebo-flagellate with two subspecies. Eur J Protistol 23:327-333

De Jonckheere JF (1993) A group I intron in the SSUrDNA of some Naegleria spp. demonstrated by polymerase chain reaction amplification. J Eukaryot Microbiol 40:179-187

De Jonckheere JF (1994a) Comparison of partial SSU rDNA sequences suggests revision of species names in the genus Naegleria. Eur J Protistol 30:333-341

De Jonckheere JF (1994b) Riboprinting of Naegleria spp.: small-subunit versus large-subunit rDNA. Parasitol Res 80:230-234

De Jonckheere FJ (1998) Sequence variation in the ribosomal internal transcribed spacers including the 5.8S rDNA of 
Naegleria spp. Protist 149:221-228

De Jonckheere JF, Brown S (1999) SSU rDNA analysis reveals the existence of a second Naegleria sp. with dividing flagellates: N. robinsoni sp. nov. Eur J Protistol 35:264-266

De Jonckheere JF, Pernin P, Scaglia M, Michel R (1984) A comparative study of 14 strains of Naegleria australiensis demonstrates the existence of a highly virulent subspecies: $N$. australiensis italica n spp. J Protozool 31:324-331

Dyková I, Macháčková B, Pecková H (1997) Amoebae isolated from organs of farmed tilapias, Oreochromis niloticus. Folia Parasitol 44:81-90

Embley TM, Dyal P, Kilvington S (1992) A group I intron in the small subunit ribosomal RNA gene from Naegleria andersoni ssp. andersoni strain PPMFB6. Nucleic Acids Res 20:6411

Franke ED, Mackiewicz JS (1982) Isolation of Acanthamoeba and Naegleria from the intestinal contents of freshwater fishes and their potential pathogenicity. J Parasitol 68: 164-166

Maslov DA, Lukeš J, Jirků M, Simpson L (1996) Phylogeny of trypanosomes as inferred from the small and large subunit rRNAs: implications for the evolution of parasitism in the trypanosomatid protozoa. Mol Biochem Parasitol 75: $197-205$

Page FC (1967) Taxonomic criteria for limax amoebae, with description of 3 new species of Hartmannella and 3 of

Editorial responsibility: Wolfgang Körting,

Hannover, Germany
Vahlkampfia. J Protozool 14:499-521

Page FC (1975) Morphological variation in the cyst wall of Naegleria gruberi (Amoebida, Vahlkampfiidae). Protistologica 11:195-204

Pélandakis M, Serre S, Pernin P (2000) Analysis of the 5.8S rRNA gene and the internal transcribed spacers in Naegleria spp. and in $N$. fowleri. J Eukaryot Microbiol 47: 116-121

Pernin P, De Jonckheere JF (1996) Naegleria pussardi, a new Naegleria species phylogenetically related to the high temperature tolerant species at the molecular level. Eur J Protistol 32:403-411

Pussard M, Pons R (1979) Étude des pores kystiques de Naegleria (Vahlkampfiidae-Amoebida). Protistologica 15: 163-175

Taylor PW (1977) Isolation and experimental infection of freeliving amoebae in freshwater fishes. J Parasitol 63:232-237

Thompson JD, Gibson TJ, Plewniak F, Jeanmougin F, Higgins DG (1997) The CLUSTALX windows interface: flexible strategies for multiple sequence alignment aided by quality analysis tools. Nucleic Acids Res 25:4876-4882

Webb SR, Brown BL, McIninch SP, Garman GC (1998) Pathogenic amoebae affecting fish in tidal freshwater James River. Proceedings of the Third International Symposium on Aquatic Animal Health. August 30-September 3, 1998, Baltimore, p 109

Submitted: February 3, 2001; Accepted: April 4, 2001 Proofs received from author(s): August 15, 2001 